This item was submitted to Loughborough's Research Repository by the author.

Items in Figshare are protected by copyright, with all rights reserved, unless otherwise indicated.

\title{
Design for sustainable behaviour
}

PLEASE CITE THE PUBLISHED VERSION

https://www.routledge.com/Routledge-Handbook-of-Sustainable-Product-

Design/Chapman/p/book/9781138910171

\section{PUBLISHER}

(C) Taylor and Francis (Routledge)

\section{VERSION}

AM (Accepted Manuscript)

\section{PUBLISHER STATEMENT}

This work is made available according to the conditions of the Creative Commons Attribution-NonCommercialNoDerivatives 4.0 International (CC BY-NC-ND 4.0) licence. Full details of this licence are available at: https://creativecommons.org/licenses/by-nc-nd/4.0/

\section{LICENCE}

CC BY-NC-ND 4.0

\section{REPOSITORY RECORD}

Lilley, Debra, and Garrath T. Wilson. 2019. "Design for Sustainable Behaviour". figshare. https://hdl.handle.net/2134/26401. 


\title{
Design for Sustainable Behaviour
}

\author{
Debra Lilley and Garrath T. Wilson, Loughborough Design School, Loughborough \\ University, UK
}

\begin{abstract}
The global impact of designed goods and the role designer's play in accelerating rapid, conspicuous consumption has long been recognised within the profession. As such, considerable effort has been directed towards reducing or mitigating negative environmental impacts caused by mass-manufacture and disposal through so called 'end of pipe' solutions. Less attention, however, has been placed on reducing the impact of use despite tacit acknowledgement amongst the design community that sustainable designs cannot reach their full potential without targeting user behaviour. Through increased focus on behaviour, and the implementation of suitably informative or persuasive strategies, designers can purposefully alter the way users interact with products to leverage more sustainable use patterns. This chapter provides design practitioners with an introduction to Design for Sustainable Behaviour (DfSB). This is an emergent field of design practice which seeks to understand user behaviour in order to drive the development of products which encourage more sustainable use. Integrating inspirational case study examples drawn from their own and others' practice, the authors chart the origins of DfSB and describe its theories, strategies and design processes. Tools to aid strategy selection are introduced and key ethical considerations reflected on in relation to specific design phases. The authors offer practical advice on designing, installing and evaluating design interventions based on experience and conclude with a discussion of the current limitations and potential future developments in DfSB.
\end{abstract}

Keywords: Sustainable behaviour, user centred design, design strategies

\section{Introduction}

In its broadest sense, this chapter is about how we, as design practitioners, can influence or control the behaviour of an individual, and by extension, society, in order to realise a more sustainable world. It is about the design processes, the psychological theories and user-centred design methods that enable us to understand, target, intervene and evaluate our way to a viable and sustainable behaviour change solution whilst also considering and reflecting upon the 
ethical issues and debates that surround what some may consider to be a provocative field of design intent and application. Given the complexity of the designer's task and the potentially volatile nature of its output if improperly executed, this chapter has been structured to enable those new to the field to get to grips comfortably with the key themes and arguments, illuminated with examples. This chapter will, in effect, act as a beginner's guide for designer practitioners when undertaking a project that concerns, what is termed, Design for Sustainable Behaviour.

Design for Sustainable Behaviour (DfSB) is an evolving field of design research and practice which sits within the broader context of sustainable design (Wever, 2012; Bhamra and Lilley, 2015). It is concerned with the application of behavioural theory to understand users, and behaviour changing strategies to design products, services and systems that encourage more sustainable use. Since its conception in the mid-2000s (Rodriguez and Boks, 2005; Lilley et al., 2006) a small yet dedicated community of scholars have contributed to the advancement of theories, strategies and design processes for DfSB. However, although there is a lively degree of debate concerning the nuances within DfSB, actively encouraged given the relative immaturity of the field, there is an emerging consensus on what constitutes a DfSB design process. The DfSB design process typically follows a sequence of five phases:

- the forming of an understanding of the user's actions in context;

- the informed selection of a behavioural target;

- the selection of a single or multiple corresponding behavioural intervention strategy(ies);

- the production of appropriate behavioural intervention design solutions;

- and, the evaluating of the behavioural intervention against the specified target behaviour. 


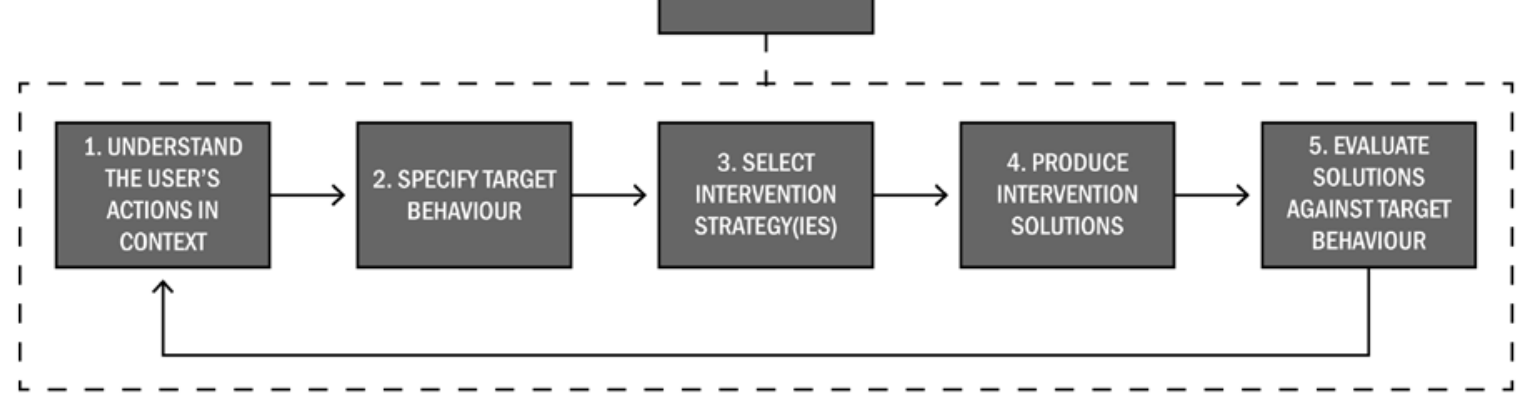

\section{Figure 1: Design for Sustainable Behaviour Design Process}

As depicted in Figure 1, though not explicitly a phase in its own right, consideration should be given, throughout the design process, to potential ethical issues which may arise in relation to data collection, the selection of target behaviours and strategies and the resulting behaviour created through the intervention designed (Lilley and Wilson, 2013).

The following sections unpack each of the phases illustrated in Figure 1 in more detail to form a comprehensive guide.

\section{Understanding users in context}

Deeper understanding of user's intentions and resulting behaviours is crucial as it enables the designer to challenge and affect habit formation (Wilson et al., 2015) - often considered to be at the root of routinized resource consumption. Through increased focus on behaviour, designers can alter the way users interact with products to leverage more sustainable use patterns by shaping individual's perception, learning, and interaction (Tang and Bhamra, 2009). In order to achieve the goal of influencing a change in behaviour towards more sustainable action, it is critical to not only understand the consequences of action but, what is also required, is an understanding of the internal and external factors that influence user action. On a broader scale, a deeper understanding of the context of use allows the facilitating and impeding conditions of infrastructure (such as physical affordances and constraints, as well as social norms, rules and laws) to be interrogated and potentially leveraged.

Models simplify the complexities of behaviours by giving them a tangible and comprehendible form (Darnton, 2008). By integrating and assimilating models from behavioural psychology into DfSB an opportunity is presented to explore and understand the 
multiple facets driving behaviour (Zachrisson Daae, 2014) through a simplified representation of extremely complex, and often quite individualistic, social and psychological structures (Chatterton, 2011). Thus, by disassembling and looking at the component parts of the behavioural construct, those seeking to modify behaviour through design can understand its underlying formation and antecedal structure, whilst also uncovering multiple points for intervention (Jackson, 2005; Chatterton, 2011). A psychological behavioural model, if we take the broad perspective that the focus is on the individual as the origin or actor of behaviour, is also considered to be a rational decision making process (rational in terms of being a process with known variables). Therefore, if we know the intentions, habits and facilitating conditions of the user and use context (the internal and external prompts), we can understand and attempt to anticipate what the user's intention to act would be and as a consequence, the resulting behaviours and impacts (Jackson, 2005, Chatterton, 2011). These knowable features are highly attractive to those seeking to influence behaviour towards more sustainable outcomes.

Products can be used in a myriad of different ways for different purposes (Albrechtslund, 2007), depending on the user's goals. A greater understanding of the user's behaviour within the context of use can enable the designer to anticipate multiple-use patterns and resulting actions (Routarinne and Redström, 2007).

By considering and attempting to anticipate the ways in which a technology may be unintentionally appropriated or inappropriately used by intended and unintended users, the designer can be considered to be acting in a reasonably ethical manner (Berdichevsky and Neuenschwander, 1999; Fogg, 2003).

Early research in DfSB sought to identify, appropriate and assimilate models of behaviour from social psychology with varying levels of maturity. Tang and Bhamra (2008), for example, integrated Triandis’ Theory of Interpersonal Behaviour (Jackson, 2005) with Anderson's framework for the acquisition of cognitive skill (Anderson, 1982) to explore the formation of habits and the relationship between habitual strength of identified behaviours and DfSB strategies. More recently Hanratty (2015) explored the framing of behaviours in relation to hedonic, gain and normative goals through adopting behaviour framing theory (Lindenberg and Steg, 2007).

Ongoing theoretical development has resulted in a collection of models, each with their own literary basis, orientation and emphasis. Although publication dates suggest a linear creation, the development trajectory was not sequential but concurrent, thus limitations arising in one researcher's offering were often not wholly addressed and resolved in another's. As such, 
consensus on which influencing factors a comprehensive model for DfSB should incorporate has yet to be reached. A full discussion of each model cited in the current literature has, therefore, not been included in this chapter. The authors do, however, suggest that readers refer to referenced works for a more nuanced understanding of these models and their constituent factors.

In order to investigate the driving factors illustrated in such behavioural models in practice, designers typically employ a combination of user-centred design (UCD) methods (see Tang (2010) or Elias (2011), for example). For the designer, Zachrisson Daae’s classification of which UCD techniques to apply in order to access which behavioural determinants (depicted in Figure 2) provides a valuable overview to inform the selection of suitable methods. Using this matrix it is possible to effectively combine methods to target more than one behavioural determinant, thus maximising the return on investment in user research.

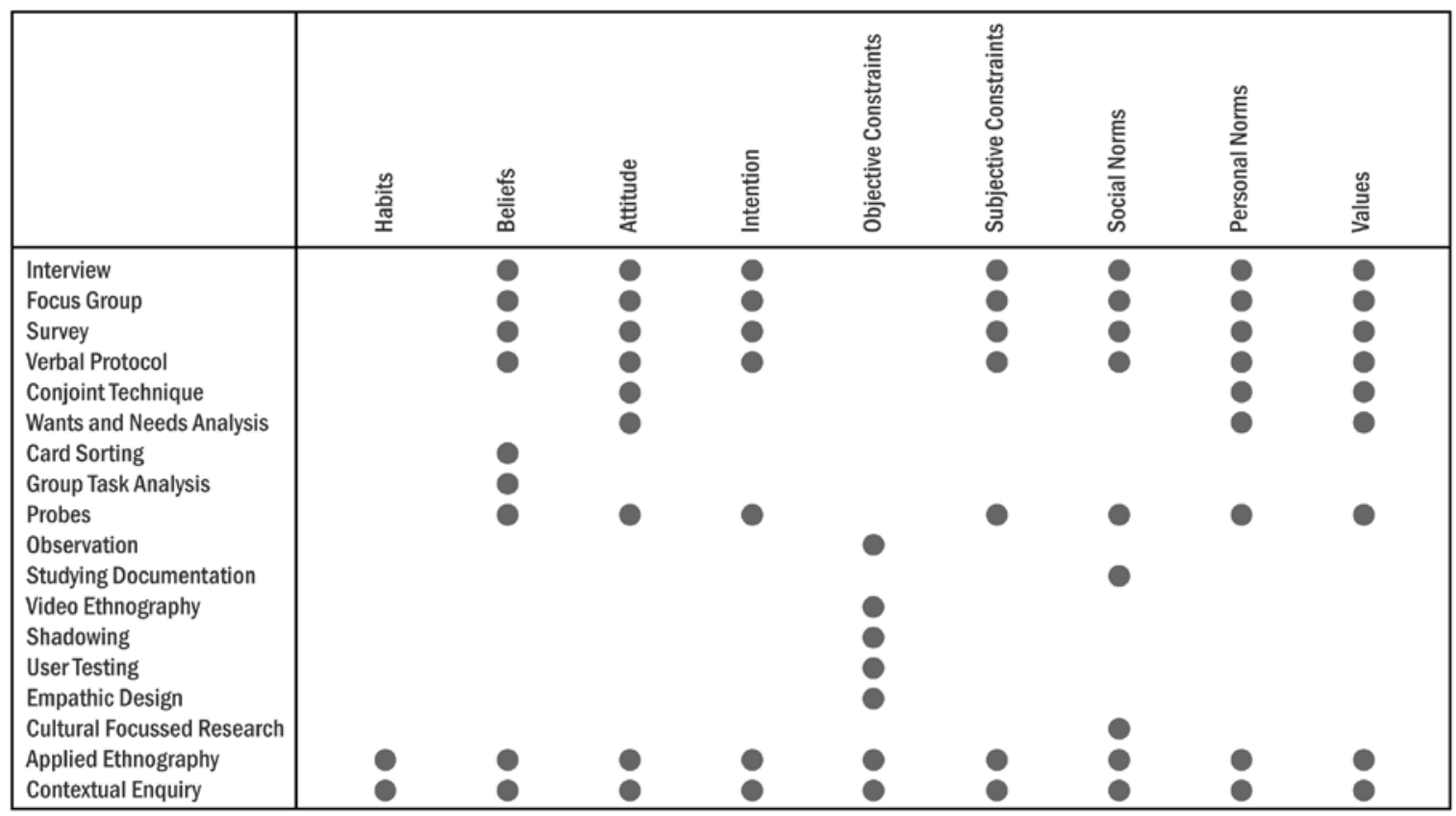

Figure 2: Matching Methods with Factors (adapted from (Zachrisson Daae, 2014))

Having reached an understanding of user behaviour in context, designers must then select, and justify the selection, of the behaviour or behaviours they intend to change as well as a single or multiple corresponding behavioural intervention strategy(ies). 


\section{Design for sustainable behaviour strategies}

Considerable attention has been given in recent years to expanding and refining the classification and categorisation of design for sustainable behaviour design strategies (e.g. Wever et al. (2008); Lilley (2009); Elias (2011); Lidman et al. (2011b); Tang and Bhamra (2011); Lockton and Harrison (2012); and Zachrisson and Boks (2012)). Boks et al.'s survey of the DfSB research community (Boks et al., 2015) however, suggests that Zachrisson and Boks (2012) taxonomy, depicted in Figure 3, is most commonly used as their main reference.

Regardless of nomenclature, what is consistent across all classifications is the presence of an axis of influence, a spectrum or continuum that illustrates control or power in decision-making, with the user or individual at one end and the product or designer diametrically positioned at the other (Lilley, 2007, 2009).

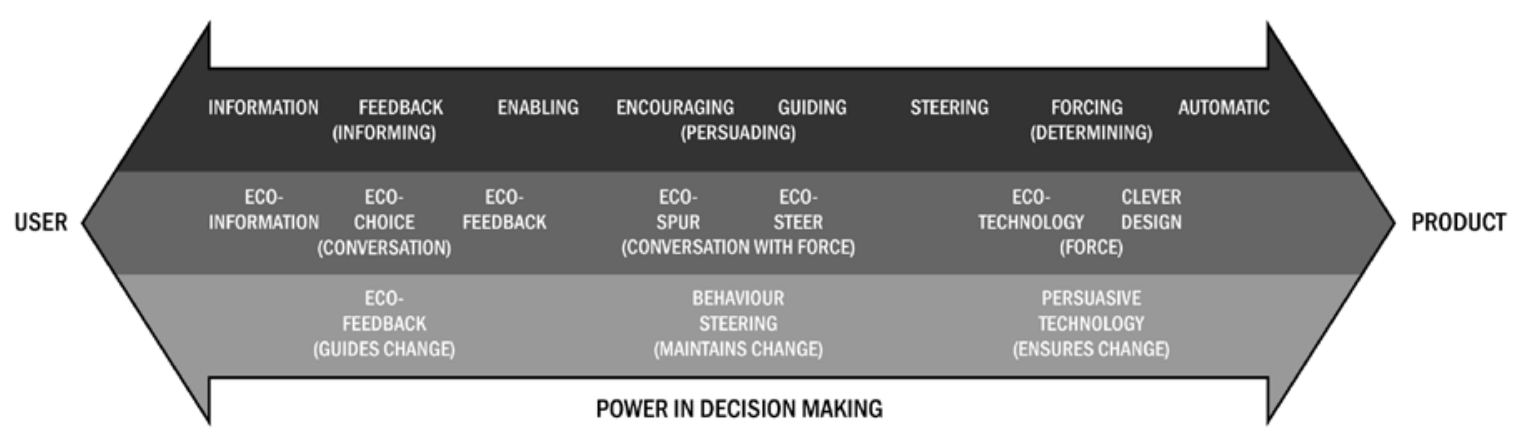

Figure 3: Axis of Influence (Lilley, 2009, Tang and Bhamra, 2011, Zachrisson and Boks, 2012)

Towards the user agentive end of this scale, are information and feedback strategies. Feedback is a method by which a product employs an overt visual, tactile or aural indicator in order to inform the user as to their actions. Due to its non-coercive, educational approach, feedback is considered to be a guide to change, enabling control of decision making to reside with the user and their individual interpretation of the feedback offered (Lilley, 2009).

Home energy management systems (HEMS) are a type of intervention that can provide instantaneous feedback on domestic energy consumption back to the user. Typically attached to the main electricity circuit of a home, information is presented via a small, portable electronic device with a numerical display. Common metrics displayed include energy (kWh consumed), environmental $\left(\mathrm{CO}_{2}\right.$ produced), or economic impact ( $£$ spent). By providing a performance indicator on the consequences of behaviour, the cognitive connection between action and effect can be strengthened, reflected and acted upon. An effective feedback mechanism should 
provide information rapidly and be tailored to the user's knowledge and value structures (Van Dam, 2013, Wilson et al., 2015).

In the centre of this proposed axis are persuading and behaviour-steering strategies (Lilley, 2009; Zachrisson et al., 2011), approaches based on Jelsma and Knot's (2002) definition of scripts but expanded to include Norman's (1988) notion of affordance; concerning the way in which a designer uses the physical or semantic characteristics of a product to prescribe a desired behaviour. By consciously scripting a product through the use of affordances (explicit potential actions), and constraints (explicit potential limitations), a designer can control the user's interaction without forcing action (Jelsma and Knot, 2002).

Most day to day products have affordances and scripts built into them as cognitive shortcuts, primarily in order for the user to be able to understand how to use them without having to go through a new, and often quite fatiguing or annoying learning process every time. Based on a socially accumulated visual language, typical examples include the push plates and pull bars on a door for opening (depending upon what side of the door you are on), and the handle and spout of a jug or teapot for lifting and pouring (Norman, 1988). An example of a product with intentional scripting to shape behaviour is the Eco Kettle by Brian Hartley which prevents the user from initially filling the heated reservoir, instead filling a secondary reservoir that then requires a conscious pushing of a plunger-like button to measure the quantity of water that the user actually wants to boil.

At the opposite end of the scale from user agentive informing strategies are forcing and determining strategies such as persuasive technology. Persuasive technology, as defined by Lilley (2009), includes Fogg's (2003) theory of captology (a synthesis of computer products and persuasive techniques) however differs by definition through the inclusion of coercive strategies to ensure change, such as intelligent context aware technologies and ubiquitous computing which negate the user's decision making processes (Lilley, 2007, 2009).

Speed bumps that force you to slow down when driving too fast, windows in an office building that open automatically on a hot day to regulate the temperature within, or Nest's smart smoke detector, Protect, that tests itself automatically, are just a few examples of products that use technology to achieve a prescribed consequence, often without the user's explicit agreement or knowledge. If This Then That (IFTTT) technology is one way by which users have started to take control of the automated process and have input, not at the point of action, but at an earlier point in time on their own terms. For example, IFTTT logic can be used 
to create user codes or 'recipes' such as if my wearable fitness band detects I have awoken, then turn on the socket that controls the space heating (Wilson et al., 2014).

As DfSB research has matured, the division between where strategies fall has been removed to present a fluid spectrum rather than an absolute categorisation (Zachrisson et al., 2011). Where a strategy fits within this axis is determined both by the actual and perceived influence of the intervention (Tromp et al., 2011). Devising reliable, defensible and practical methods to inform the selection of which behaviours to target and which corresponding strategy to use, however, has proven more challenging.

\section{Targeting behaviours and strategy selection}

If the overall aim of DfSB is to achieve more sustainable actions by users, a key concern when selecting a behavioural target is what constitutes sustainable behaviour? Whereas, environmental behaviour is considered to result in the least harm to the environment as possible (Steg and Vlek, 2009) and 'Pro-ecological behaviors are purposeful and effective actions that result in the conservation of natural resources' (Tapia-Fonllem et al., 2013); sustainable behaviour presents an expanded scope encompassing both 'actions aimed at protecting both the natural and the human (social) environments' (Tapia-Fonllem et al., 2013, p712). Different behaviours enacted by different users in different contexts, however, result in differing levels of environmental and social impact, both positive and negative. Should, therefore, behaviours be selected on the basis of the severity of their environmental and social impact? And if so, how are such impacts to be measured? And by whom? Whereas arguably key environmental priorities, such $\mathrm{CO}_{2}$ reduction, remain constant targets (aided by legislative demands), social norms are constantly shifting and what is socially unacceptable behaviour within the public realm today may well become the 'norm' in the future (take for example mobile phone use in public (Lilley, 2007)). Is the use of a more forceful intervention warranted if the potential consequences of the target behaviour are considered severely detrimental to society or the environment? Or should free will prevail in all circumstances? These questions are largely rhetorical and, as with many ethical dilemmas, have no definitive answers. It is important, however, to raise them within the designer's mind to ensure the behavioural target is wellchosen and justifiable, and furthermore, that the designer's motivation and intent is reflected upon and scrutinised.

In addition to the somewhat muddied waters of selecting a behavioural target, designers must also carefully consider how to select an appropriate strategy or strategies. Applying a 
strategy that is too forceful may be met with resistance and rejection (Brey, 2006); conversely, for a more passive strategy such as information provision to be effective the user must be sufficiently motivated to act upon the information and be willing to change (Zachrisson Daae, 2014). Forcing and determining strategies that fall within the remit of ubiquitous technology have a tremendous potential to affect sustainable behaviour. By removing the user from the decision making process an intelligent system could, based on sustainability variables, optimise and automate processes to ensure that the most sustainable action is taken; a fine balancing act between democracy/technocracy and long term sustainable goals. It is important to consider though that removing the user from the decision making process allows 'unsustainable' user actions to be negated, this also separates the user from developing an understanding of the fundamental relationships between cause and effect, potentially leading to further rebound effects and unsustainable consequences. The learning and adapting of one's behaviour in response to feedback is not an option in this more hands-off scenario.

Additionally, the value of the intervention to the user must be considered and weighed against the lack of freedom and choice. For example, an intervention that automated a process and saved the user time and money, such as a smart home thermostat, may be perceived as being more acceptable than an intervention that automatically optimised the office environment, such as automated windows. Hence, the value proposition of the intervention must be considered as well as the boundaries of what the user finds acceptable.

Zachrisson et al.'s work proposes a set of guidelines that may help the designer in the selection of an effective strategy solution, based upon the underlying construct of a psychological behavioural model (2011). Concerned with habits, intentions and constraints, values and norms, and importance/annoyance, the notion is that the designer uses a series of simplified guiding statements and illustrated axis as a tool to help inform and direct the selection of an appropriate strategy. In an early example of the guidelines, under the title of 'does the user want to behave the intended way?' there is the following guiding statement of, 'The less the user wish to perform the intended behaviour, the more control should be given to the product. Pushing the user to do something he/she does not want to do might result in the user stop using the product', under which there are several axes including user in control versus product in control, with the accompanying statement of 'only users who agree with the intended behaviour may be willing to change their behaviour based on information or feedback' (Zachrisson et al., 2011, p366); suggesting that a strategy whereby the user was in control would be an appropriate strategy if the user was willing to change their behaviour. Later iterations of the tool have further streamlined the axes and its usability for designers, resulting in several so-called Dimensions of Behaviour Change of how the design strategies should be 
applied with illustrated examples; including Meaning (emotional-reason); Exposure (rarelyfrequently); Encouragement (promote-discourage); Timing (before use-after use); Empathy (me-others); Obtrusiveness (obtrusive-unobtrusive); Importance (important-unimportant); and Direction (in line-opposing) (Zachrisson Daae, 2014; Zachrisson Daae and Boks, 2014). Though the suitability of the parameters of the chosen axes are open to debate, Zachrisson et al.'s tool provides a valuable aid to strategy selection allowing the designer to give consideration to the appropriateness of a given strategy.

Hanratty’s ‘Behaviour Intervention Selection Axis’ or BISA offers an alternative tool for strategy selection based on an understanding of the user's thought processes and associated actions in context (in this case energy consuming behaviours in the home) and their relative level of situationality or reflectiveness (Hanratty, 2015). According to the BISA "the more situational behaviour is the more it is driven by context and situation, with perhaps very little mindfulness or cognition from the individual" (ibid, p. 104), the intervention, therefore, should direct the behaviour through employing determining strategies. In a similar vein to Zachrisson et al. (2011), Hanratty also advocates that a requisite level of obtrusiveness (e.g. how much an intervention pushes itself forward into the users sphere of interaction) be applied to support the chosen strategy in order to disrupt and intervene in users routinized thought processes, particularly when dealing with highly situational behaviours (Figure 4). 


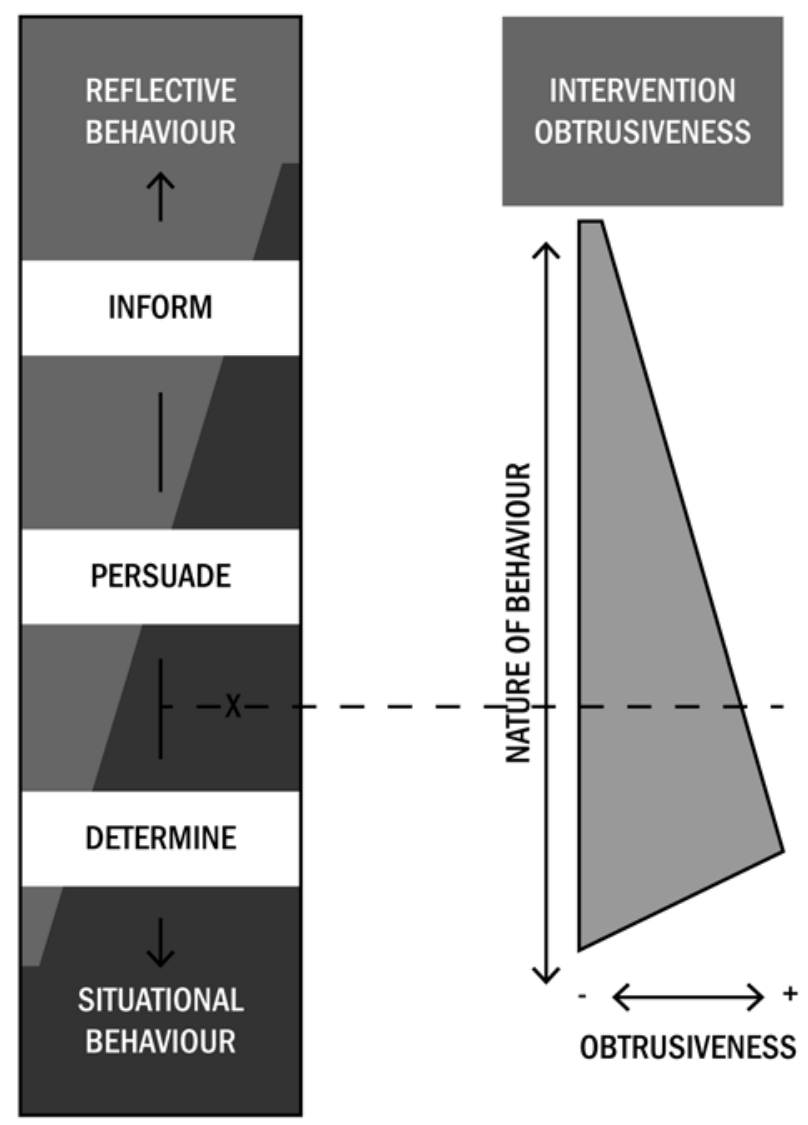

\section{$X=$ TARGETED BEHAVIOUR}

Figure 4: Required Intervention Obtrusiveness (Hanratty, 2015)

A worked example of the application of the BISA can be found in Hanratty (2015) alongside a more detailed explanation of its origin and development.

When considering the selection of target behaviours, using either model, it is worth considering if the behaviour itself needs changing at all, or if indeed the delivered product functionality is mismatched with the desired functionality of the user. For further discussion on this approach to product rather than behavioural adoption, please refer to Wever et al. (2008), Lidman et al. (2011a, 2011b) and Lidman and Renström (2011).

\section{Production of appropriate behavioural intervention design solutions}

The development of behaviour changing products has seen considerable growth with a proliferation of designs incorporating behaviour-changing strategies coming to the market in recent years (as described in the numerous examples provided in this chapter). Yet many of 
these designs have been created independently of the DfSB community and, as a consequence, lack transparency in terms of their process and theoretical underpinning. Those created by DfSB practitioners, such as the shower concept Enuf (Hanratty, 2015), have been realised to prototype stage through implementation of a user-centred design process, yet their production has been limited in number and their real-world evaluation by users in context limited in length and scope. The value of these studies, however, lies in their exemplification of the application of process and strategy.

The Enuf Shower concept (Hanratty, 2015) was predicated on an understanding of showering practices gleaned from video tours of 11 householders bathroom practices in which family members recounted their routines in context. The analysis of the data identified behavioural drivers such as hygiene, pleasure, waking-up and daydreaming, as well as uncovering relationships between users attitude towards showering (maximising efficiency) and the duration of the showering activity in relation to the participants age, with younger people tending to shower for longer. Wasteful behaviours such as allowing the water to heat up before stepping under the flow were also observed. With reference to the BISA (outlined above), Hanratty determined two key goal frames for the observed showering behaviour; normative goal frames relating to perceived social standards of hygiene was seen to drive the frequency of showering. The duration of the shower, however, was driven by a hedonic goal frame (e.g. comfort, pleasure and privacy) as well as, for those wishing to minimise the amount of time they spent showering to maximise productive time spent on other tasks, the gain goal frame. This analysis led Hanratty to frame showering as deeply situational, an activity performed on a daily basis without conscious deliberation of wasteful behaviours, therefore, the intervention designed needed to "refocus the participants' reflective attention on the task of cleaning themselves efficiently" (Hanratty, 2015 , p. 146) and as such, the level of obtrusiveness required was high. Enuf "is an automatic persuasive shower monitoring device" which uses feedback and behavioural prompts to encourage users to reduce showering times (ibid, p. 148). Through iterative development and pilot testing, Enuf was refined to eradicate operational flaws and optimise usability culminating in a 6-week user trial within 6 multi-occupancy households in the UK. To allow a direct comparison of pre and post-installation, baseline data on user behaviour was collected for a 3-4 week period, during which the device remained 'dumb'. The interactive features were then activated. A post-installation evaluation was conducted to assess Enuf's effectiveness based on the 3 questions outlined in the Evaluation section below. The trial indicated that the use of Enuf did indeed result in reduced showering times. 
The experiences of the authors, as well as those of the wider DfSB community, have led to the identification of several practical considerations to account for when designing a behavioural intervention. These are discussed below.

The value of following the entire DfSB process cannot be underestimated. It is acknowledged, however, that although students may have the opportunity (and indeed time) to engage in all phases, practitioners, on the other hand, may have a more defined, bounded role in the product development process in which contribution is limited to one or two particular phases.

Of further benefit is the inclusion of multidisciplinary perspectives in a project team, as the combination of knowledge and skills these subject-areas bring can prove invaluable in the design and implementation of behaviour-changing devices. Within the Low Effort Energy Demand Reduction (LEEDR) project (Wilson et al., 2014), for example, social scientists, engineers and product designers worked collaboratively to develop and test digital design interventions to reduce energy consumption in the private housing sector.

At each stage of the design process, lessons learnt in prior research can be applied to increase the potential for achieving a successful design outcome. When entering the user research phase, for example, consideration should be given to the sample size. Traditionally user-centred studies utilizing qualitative methods tend to favour depth over breadth, resulting in a deep understanding of a specific cohort rather than a statistically significant survey of a larger populous. The value of this rich data should not be undervalued, however, as from the specific, broader conclusions can be extrapolated and tested with a larger, more representative sample; thereby adding to the applicability, validity and reliability of the data. One must also consider who the primary evaluative target user will be, whilst also taking into account the influence of other occupants. Within the Carbon, Control and Comfort research project (Wilson, 2013), for example, a household within Merthyr Tydfil, Wales was occupied by a mother and daughter who each expressed different levels of acceptability in terms of thermal comfort. Their relative need for warmth resulted in one occupant (the mother) reducing local room temperature via a thermostatic radiator valve whilst another occupant (the daughter) raised the overall household temperature via the central thermostat in the hall.

Although there may be a temptation to use labour-saving methods, such as existing studies, tools or resources, the use of these in isolation is not recommended. User research can certainly be time-consuming; however, its value in aiding deep comprehension of behaviour in context and building empathy with users is unparalleled. Tools to aid strategy selection and 
ideation for DfSB can prove useful inspiration for ideation but they are not a substitution for actual user research. Similarly, drawing on user data generated by others, through practical and potentially time-saving, can prove problematic unless the approach is standardized to enable sharing.

There are several design tools that could aid the designer in designing an appropriate solution, including the Fogg Behavior Grid (Fogg and Hreha, 2010); the Design with Intent toolkit (Lockton et al., 2010); the Dimensions of Behaviour Change tool (Zachrisson Daae and Boks, 2014); Lilley \& Lofthouse’s weighted ethical matrix (2010); and the Design Behaviour website (www.design-behaviour.co.uk) . Such tools may be appropriate for facilitating discussion, debate and reflection on the pertinent issues within a design team but it is important to remember that these tools and toolkits are not to be used prescriptively, or as a substitute for understanding the user's behaviour or evaluating an intervention in a real-world context.

Throughout the design development process, the researcher/designer should be cognizant of the fact that they, themselves are an intervention. Without active mindfulness, potential bias may be inflicted through the design choices made, through interaction with users and via the evaluative process. Though objectivity is challenging to maintain when dealing with an artistic endeavour, care should be taken to avoid undue influence. The framing of the initial approach to users, for example, needs to be scrutinized to ensure materials do not lead participants towards a particular behavioural outcome or instigate a premature change in behaviour in response to external prompts. For example, framing the introduction of an intervention intended to reduce energy consumption in explicit terms may trigger other energysaving behaviours to be enacted. Similarly, the mere presence of the researcher may result in participants consciously or subconsciously altering their behaviour due to their awareness of being observed, a phenomenon known as the Hawthorne effect (Roethlisberger and Dickson, 1939). Allowing participants to acclimatise to the device in-situ for a period of time before activating any interactive behaviour-changing features may, however, ameliorate these effects (Hanratty, 2015).

The selection of a strategy or strategies, and the level of persuasion they impose, as discussed previously, should be approached cautiously. The potential for failure in adoption of desired behaviours or possible rebound effects or game-playing (escalation of impact as opposed to reduction to beat the device) is a distinct reality if the strategy chosen is too forceful or controlling. A weak strategy employed to combat ingrained, habitual behaviours within an obstinate user unwilling to change, however, is unlikely to be effective or sustained. A user's willingness to change can be informed by the fit between the behaviour the designer intends to 
create and previously practiced behaviours (Cialdini, 2001). Yet willingness alone is not sufficient, the circumstances to enable change to happen must also be aligned. Impediments to change are not only structural, such as access to recycling facilities, but also temporal, such as the day of collection. In a study investigating user perceptions towards retrofitting of energysaving measures within domestic environments, for example, the occupant's stage of life was found to forestall or even prevent home improvements (Mallaband et al., 2013). These life stages, which spanned the birth of a child to the advent of old age, were seen by some as obstructions, yet potentially these and other life changes could signal an opportunity to leverage change by providing the motivation in which to act. Understanding the most opportune moments to intervene to ensure successful adoption of new behaviours, therefore, is also a key concern. Within academic research projects the intervention installation period is often determined by project time scales, and may not necessarily constitute the optimum time from the user/behaviour perspective. Though not explicitly explored within DfSB research at present, the integration of theory concerning a user's susceptibility to embrace change, such as the Transtheoretical Model (Prochaska and DiClemente, 2005), may prove beneficial in informing the point of intervention.

The evaluative phase is, in practice, preceded by the installation of the designed device into the context of use. First and foremost, it is necessary to decide upon the length of the testing period as this will determine other practical design features; such as the power supply, participant compensation and data monitoring plan (if consumption data is to be gathered). Having identified the period of testing, the researcher should take steps to ensure the device will function for the full duration of product testing; this may include the choice of power supply (e.g. batteries functional lifespan). They should also try, where possible, to reduce contamination of user evaluation by limiting any discussion or explanation when servicing the device in situ (Hanratty, 2015). Whilst installed, ethical and health and safety issues which may arise; for example, does the intervention draw on the household or workplace energy supply to function? And if so, have participants been duly compensated for any costs they may incur?

All of these issues have the potential to hinder the successful execution of a DfSB intervention; however, with due attention and scrutiny none are insurmountable.

\section{Evaluation}

The final stage of the DfSB process is evaluation, yet, surprisingly, this phase has received relatively little attention by scholars. Given the nascent state of Design for Sustainable Behaviour and the lack of longitudinal case studies, especially those that follow through the 
DfSB design process in its entirety, it is not surprising that there is no one single model or categorisation of intervention strategies to which all those practising under this banner subscribe. DfSB is still evolving and many debates are still to be had; that is a good thing. Yet, the lack of a unified framework by which to assess the effectiveness of different strategies in achieving sustained behaviour change has proven to be a hindrance in proving their worth. What is needed to progress the field, and arguably, propel these strategies further into commercial application, is a reliable method of evaluation which demonstrates tangible sustainability improvement. The evaluation of a DfSB intervention can be disaggregated into three core components; an evaluation of the usability and function of the designed intervention itself (questions dependent upon the DfSB strategy); an evaluation of the ecological, social and economic impact of the intervention (questions dependent upon the intervention context); and an evaluation of the resulting change in user behaviour due to intervention (questions applicable to all DfSB strategies) (Wilson et al., 2013, Wilson et al., 2015).

By disaggregating and formalising the evaluation questions, multiple entry points for analysis can individually or collectively be explored in order to iteratively feed back into the design process as well as for cross-study comparison. This approach gives a more threedimensional account of the impact of an intervention and avoids the somewhat prevalent and very limited view of only categorising a behaviour changing interventions success as a percentage reduction in a single sustainability metric (e.g. intervention x reduced energy consumption by y\%). Such a limited account not only precludes any evaluation of the actual behaviour change mechanism itself, and by extension how it could be improved through the design process, but also makes the incorrect supposition that a change in behaviour equates directly to a change in, for example, consumption (which we know not to be true due to rebound effects).

\section{Does the design intervention function for the specified context?}

Is the usability of the design in line with the user's requirements and expectations, and do the design functions operate as the designer intended? Clearly different DfSB strategies have different criteria against which to assess usability and function and as such questions related to the design of the intervention, for example, how does the accuracy of the feedback information help the user to associate with their actions?, are clearly weighted towards feedback alone and are not applicable to other strategies. The overarching question is still valid, does the design intervention function for the specified context?; however, if such specific sub-questions were to be applied to a different strategy then the sub-questions would need to be more appropriate to 
the intervention strategy and mechanisms employed. Feedback seeks to change behaviour through the provision of information and therefore the sub-questions required are related to this. If one was considering the evaluation of a persuasive or behaviour steering intervention then questions related to cognitive interaction expectations (such as design semiotics) and the use and performance of affordances and constraints (perhaps requiring a physical ergonomics assessment) would be required. Forcing and determining strategies that could entirely negate the user's interaction would perhaps need to be evaluated in terms of installation issues and the requirements of monitoring or maintaining the technology. In short, these sub-questions are dependent upon the strategy.

\section{Is the change in the user's behaviour sustainable?}

Through an understanding and measurement of the change in sustainability metrics, the success of a DfSB intervention can be put into perspective against the interventions function and ability to change the user's behaviour. Whilst sustainability is commonly defined in terms of economic, environmental and social pillars (Bhamra and Lofthouse, 2007), each of these pillars are contextual. For example, an intervention may be concerned with reducing the amount of CO2 (environment) generated from domestic energy consumption, whilst ensuring that comfort (social) is increased, and that financial burden (economy) is reduced. Interventions with different aims and contexts will require different project specific sustainability impact criteria.

Questions that evaluate the ethical impact of changing the user's behaviour and the ethics of the process itself are not tied to any strategy or context, and are applicable to all design interventions. However, it should be noted that ethical questions asked should not be moralistic, rather they are a proposition of considerations by the designer. They should not be solely reflective, but as a platform from which to integrate other relevant perspectives. Rather than stating that 'the motivations behind the creation of a persuasive technology should never be such that they would be deemed unethical if they led to a more traditional persuasion' (Berdichevsky and Neuenschwander, 1999, p52), it would perhaps be more logical to ask 'was the designer's original motivation for designing a behaviour intervention ethical?' This allows for a wider discussion with the user and other stakeholders without relying on the fragile premise of a universal moral framework. Instead, decisions can be made in reference to the moral frameworks of relevance. 


\section{Has the user's behaviour changed as a consequence of the design intervention?}

The goal of DfSB is to create long-term sustainable behaviour change. Questions have to be asked of a DfSB interventions ability to change the habitual behaviour of the user, and therefore, in order to determine if the user's behaviour has changed due to the intervention. It is also necessary to understand the antecedents and the habitual strength of that behaviour targeted for change (i.e. the behavioural baseline).

As outlined previously, by taking a psychological approach, behaviour can be viewed as being a rational decision making process with the individual, or typically termed the user within a design context, being the central actor (Jackson, 2005, Chatterton, 2011). Others, such as Kuijer (2014) and Pettersen (2013) prefer conceptualising human action in terms of social practice theory, but generally speaking, this is less ontologically aligned with current design practice. Given internal or external stimulus, within this rational process, habits (characterised by frequency of past behaviour and cognitive automaticity) have an overriding priority factor over intention (attitude, social factors and effect), with both intention and habits in turn both ruled by facilitating conditions (external constraining factors, such as situational context) (Bargh, 1994; Jackson, 2005; Verplanken, 2006; Chatterton, 2011). Based on this definition, evaluation questions must focus on changes in context, intentions and cognitive automaticity. For example:

- Did the facilitating conditions constrain or afford opportunities for change?

- Did the users perception of self-concept change?

- Did the user have difficulty in controlling the intended behaviour?

Although behaviour itself is dependent on the specific user and the specific context, the same questions need to be asked as the antecedents of behaviour are present within all action habitual or not.

To effectively evaluate the impact of a designed intervention, qualitative and quantitative data on existing behaviour within the context of use (a baseline) and behaviour post-intervention is required. Establishing a baseline of existing behaviour in context allows any changes or improvements to behaviour derived from the intervention to be measured and quantified in relation to existing influences. This is vital if the efficacy of the intervention is to be demonstrated. Data may be captured through the use of qualitative research techniques, such as observation (Tang and Bhamra, 2012) or, quantitative measurement, such as the length of 
time a refrigerator door is open, or the number of products correctly disposed of (Elias et al., 2008a; Elias et al., 2008b; Wever et al., 2010). Or ideally, as in Hanratty (2015) - who conducted in-home ethnographic studies as well as capturing energy and water consumption data - a combination of both. In some cases, if considered within the conceptual phase, the device itself can be designed to enable baseline data to be accrued before activating any interactive features, as was the case with the Enuf (Hanratty, 2015). Although the quantitative techniques lack the in-depth understanding of behaviour afforded through qualitative investigation (behaviour is not measured just by number of repetitions of action), both of these approaches offer different perspectives on how to assess the behaviour of the user and the relative impact of their actions.

\section{Conclusions}

This chapter has provided a guide to designing interventions for behaviour change towards sustainable actions for the product design practitioner. It has highlighted the importance of understanding user behaviour in context to appropriately target behaviours to change and provided models and tools to identify behavioural determinants. Two different tools to select behavioural change strategies have been introduced and guiding questions for evaluation of the resulting design outcome provided. The ethical considerations designers should take into account at each stage of the DfSB design process have been elucidated for reflection.

The field of DfSB is growing rapidly; however, there are notable gaps in knowledge which are yet to be addressed. Though strategies differ in their nomenclature, consensus has coalesced around the axis of influence. Furthermore, strategy selection has been strengthened through the development of the Dimensions of Behaviour Change tool and Behavioural Intervention Selection Axis. However, matching the relative severity or significance of the behaviour identified with the strength of an intervention has yet to be firmly established and further guidance is needed. The most obvious omission to the DfSB domain, however, is the lack of real-world application of its strategies and processes to establish their effectiveness in achieving sustained, sustainable behavioural change.

The pressing need to address social and environmental impacts resulting from product use is paramount. We, as design researchers and practitioners, have a unique opportunity to harness the power of design to positively, and ethically, influence user behaviour to create a more sustainable world. Using the tools, strategies and processes outlined in this chapter it is hoped that a new generation of practitioner designers will be inspired to engage in this new and exciting field, and in doing so, further support its evolution. 


\section{References}

Anderson , J. R. (1982) ‘Acquisition of Cognitive Skill’, Psychological Review, vol 89, pp369406

Albrechtslund, A. (2007) 'Ethics and Technology Design', Ethics and Information Technology, vol 9, No 1, pp63-72

Bargh, J. A. (1994) 'The Four Horsemen of Automaticity: Awareness, Efficiency, Intention, and Control in Social Cognition', in R. S. Wyer, J. \& Srull, T. K. (Eds) Handbook of Social Cognition, 2nd ed, Hillsdale, NJ:Erlbaum, pp1-40

Berdichevsky, D. \& Neuenschwander, E. (1999). 'Toward an Ethics of Persuasive Technology', Communications of the ACM, vol 42, No 5, pp51-58

Bhamra, T. A. \& Lilley, D. (2015) 'IJSE Special Issue: Design for Sustainable Behaviour', International Journal of Sustainable Engineering, vol 8, No 3, pp146-147

Bhamra, T. A. \& Lofthouse, V. A. (2007) Design for Sustainability A Practical Approach, Gower Publishing Limited

Boks, C., Lilley, D. \& Pettersen, I. N. (2015) The Future of Design for Sustainable Behaviour, Revisited. Proceedings of EcoDesign 2015, 2-4 December, Tokyo, Japan

Brey, P. (2006) 'Ethical Aspects of Behavior Steering Technology', in Verbeek, P. P. \& Slob, A. (Eds) User Behavior and Technology Development: Shaping Sustainable Relations Between Consumers and Technologies, Kluwer, pp357-364

Chatterton, T. (2011) An Introduction to Thinking About 'Energy Behaviour': A Multi Model Approach, Department for Energy and Climate Change, London

Cialdini, R. (2001) Influence: Science and Practice, Allyn \& Bacon

Darnton, A. (2008) GSR Behaviour Change Knowledge Review: An Overview of Behaviour Change Models and their Uses, Government Social Research Unit, London

Elias, E. W. A. (2011) User-efficient Design: Reducing the Environmental Impact of User Behaviour Through the Design of Products, Doctor of Philosophy, University of Bath

Elias, E. W. A., Dekoninck, E. A. \& Culley, S. J. (2008a) Assessing user behaviour for changes in the design of energy using domestic products. Proceedings of the 2008 IEEE International Symposium on Electronics and the Environment, 2008a. IEEE Computer Society

Elias, E. W. A., Dekoninck, E. A. \& Culley, S. J. (2008b) Prioritisation Methodology for the User-Centred Design of Energy Using Domestic Products. International Design Conference - DESIGN 2008, 19-22 May, Dubrovnik, Croatia

Fogg, B. J. (2003) Persuasive Technology: Using Computers to Change What We Think and Do (Interactive Technologies), Morgan Kaufmann 
Hanratty, M. (2015) Design for Sustainable Behaviour: A Conceptual Model and Intervention

Selection Model for Changing Behaviour Through Design, Doctor of Philosophy, Loughborough University

Jackson, T. (2005) Motivating Sustainable Consumption: A Review of Evidence on Consumer Behaviour and Behavioural Change, a Report to the Sustainable Development Research Network, Centre for Environmental Strategy, University of Surrey

Jelsma, J. \& Knot, M. (2002) 'Designing environmentally efficient services: a 'script' approach', The Journal of Sustainable Product Design, vol 2, pp119-130

Kuijer, L. (2014). Implications of Social Practice Theory for Sustainable Design, Doctor of Philosophy, TU Delft

Lidman, K. M. E. \& Renström, S. E. (2011) How to Design for Sustainable Behaviour? - A Review of Design Strategies \& an Empirical Study of Four Product Concepts, Master of Science, Chalmers University of Technology

Lidman, K. M. E., Renström, S. E. \& Karlsson, I. C. M. (2011a) The Green User: Design for Sustainable Behaviour. in Roozenburg, N. F. M., Chen, L. L. \& Stappers, P. J., eds Diversity and Unity, IASDR2011, The 4th World Conference on Design Research, 31 October - 4 November, Delft, The Netherlands

Lidman, K. M. E., Renström, S. E. \& Karlsson, I. C. M. (2011b) I Don't Want to Drown the Frog! A Comparison of Four Design Strategies to Reduce Overdosing of Detergents. Proceedings from Conference on Sustainable Innovation 2011, 'Towards Sustainable Product Design', Farnham, UK

Lilley, D. (2007) Designing for Behavioural Change: Reducing the Social Impacts of Product Use Through Design, Doctor of Philosophy, Loughborough University

Lilley, D. (2009) 'Design for sustainable behaviour: strategies and perceptions', Design Studies, vol 30, No 6, pp704-720

Lilley, D., Bhamra, T. A. \& Lofthouse, V. A. (2006) Towards Sustainable Use: An Exploration of Designing for Behavioural Change. DeSForm 2006: European Workshop on Design and Semantics of Form and Movement, 2006, Eindhoven, The Netherlands, pp84-96

Lilley, D. \& Lofthouse, V. A. (2010) 'Teaching Ethics For Design For Sustainable Behaviour: A Pilot Study', Design and Technology Education: An International Journal, vol 15, No 2

Lilley, D. \& Wilson, G. T. (2013) 'Integrating Ethics into Design for Sustainable Behaviour', Journal of Design Research, vol 11, No 3, pp278-299

Lockton, D. \& Harrison, D. (2012) 'Models of the User: Designers' Perspectives on Influencing Sustainable Behaviour', Journal of Design Research, vol 10, No 1/2, pp7-27

Lockton, D., Harrison, D. \& Stanton, N. (2010) 'The Design with Intent Method: A Design tool for Influencing User Behaviour', Applied Ergonomics, vol 41, No 3, pp382-392 
Mallaband, B., Haines, V. \& Mitchell, V. (2013) 'Barriers to domestic retrofit: learning from past home improvement experiences', in Swan, W. \& Brown, P. (Eds) Retrofitting the Built Environment, Wiley-Blackwell, Chichester, West Sussex

Norman, D. (1988) The Psychology Of Everyday Things, Basic Books

Pettersen, I. N. (2013) The Role of Design in Supporting the Sustainability of Everyday Life, Doctor of Philosophy, Norwegian University of Science and Technology

Prochaska, J. O. \& Diclemente, C. C. (2005) 'The Transtheoretical Approach', in Norcross, J. C. \& Goldfried, M. R. (Eds) Handbook of Psychotherapy Integration, Oxford University Press, New York, pp147-171

Rodriguez, E. \& Boks, C. (2005) How Design of Products Affects User Behaviour and Vice Versa: the Environmental Implications. Environmentally Conscious Design and Inverse Manufacturing, 2005. Eco Design 2005. Fourth International Symposium on, 12-14 December 2005, pp54-61

Roethlisberger, F. J. \& Dickson, W. J. (1939) Management and the Worker: An Account of a Research Program Conducted by the Western Electric Company, Hawthorne Works, Harvard University Press, Chicago

Routarinne, S. \& Redström, J. (2007) Domestication as Design Intervention. Design Inquiries 2007, 27-30 May, Stockholm, Sweden

Steg, L. \& Vlek, C. (2009) 'Encouraging pro-environmental behaviour: An integrative review and research agenda', Journal of Environmental Psychology, vol 29, No 3, pp309-317

Tang, T. (2010). Towards Sustainable Use: Design Behaviour Intervention to Reduce Household Environmental Impact, Doctor of Philosophy, Loughborough University

Tang, T. \& Bhamra, T. A. (2009) Improving Energy Efficiency of Product Use: An Exploration of Environmental Impacts of Household Cold Appliance Usage Patterns. 5th International Conference on Energy Efficiency in Domestic Appliances and Lighting, 18 June 2009, Berlin, Germany

Tang, T. \& Bhamra, T. A. (2011) Applying a Design Behaviour Intervention Model to Design for Sustainable Behaviour. The Tao of Sustainability: An International Conference on Sustainable Design in a Globalization Context, 27th -29th October 2011, Beijing, China

Tang, T. \& Bhamra, T. A. (2012) 'Putting consumers first in design for sustainable behaviour: a case study of reducing environmental impacts of cold appliance use', International Journal of Sustainable Engineering, vol 5, No 4, pp288-303

Tapia-Fonllem, C., Corral-Verdugo, V., Fraijo-Sing, B. \& Duron-Ramos, M. F. (2013) 'Assessing Sustainable Behavior and its Correlates: A Measure of Pro-Ecological, Frugal, Altruistic and Equitable Actions', Sustainability, vol 5, No, pp711-723 
Tromp, N., Hekkert, P. \& Verbeek, P. P. (2011) 'Design for Socially Responsible Behavior: A Classification of Influence Based on Intended User Experience', Design Issues, vol 27, No 3, pp3-19

Van Dam, S. S. (2013) Smart Energy Management for Households: A Practical Guide for Designers, HEMS Developers, Energy Providers, and the Building Industry, CreateSpace Independent Publishing Platform

Verplanken, B. (2006) 'Beyond Frequency: Habit as Mental Construct', British Journal of Social Psychology, vol 45, pp639-656

Wever, R. (2012) 'Editorial', Journal of Design Research, vol 10, No 1/2, pp1-7

Wever, R., Van Kuijk, J. \& Boks, C. (2008) 'User-centred design for sustainable behaviour', International Journal of Sustainable Engineering, vol 1, No 1, pp9 - 20

Wever, R., Van Onselen, L., Silvester, S. \& Boks, C. (2010) 'Influence of Packaging Design on Littering and Waste Behaviour', Packaging Technology and Science, vol 23, No 5, pp239-252

Wilson, G. T. (2013) Design for Sustainable Behaviour: Feedback Interventions to Reduce Domestic Energy Consumption, Doctor of Philosophy, Loughborough University

Wilson, G. T., Bhamra, T. \& Lilley, D. (2015) 'The considerations and limitations of feedback as a strategy for behaviour change', International Journal of Sustainable Engineering, vol 8, No 3, pp186-195

Wilson, G. T., Leder Mackley, K., Mitchell, V., Bhamra, T. A. \& Pink, S. (2014) PORTS: an interdisciplinary and systemic approach to studying energy use in the home. UbiComp '14 Adjunct, September 13-17 2014, Seattle, WA, USA

Wilson, G. T., Lilley, D. \& Bhamra, T. A. (2013) Design Feedback Interventions for Household Energy Consumption Reduction. Proceedings of ERSCP-EMSU 2013 Conference, 4th-7th June 2013, Sustainable Development and Cleaner Production Center, Boğaziçi University, Istanbul, Turkey

Zachrisson Daae, J. (2014) Informing Design for Sustainable Behaviour, Doctor of Philosophy, Norwegian University of Science and Technology

Zachrisson Daae, J. \& Boks, C. (2014) 'Dimensions of Behaviour Change', Journal of Design Research, vol 12, No 3, pp145-172

Zachrisson, J. \& Boks, C. (2012) 'Exploring Behavioural Psychology to Support Design for Sustainable Behaviour', Journal of Design Research, vol 10, No 1/2, pp50-66

Zachrisson, J., Storrø, G. \& Boks, C. (2011) Using a Guide to Select Design Strategies for Behaviour Change; Theory vs. Practice. Proceedings of EcoDesign 2011 International Symposium, Kyoto, Japan 